\title{
Transcription Factors Underlying the Development and Endocrine Functions of the Placenta
}

\author{
James C. Cross, ${ }^{* \dagger}$ Lynn Anson-Cartwright, ${ }^{\dagger}$ and Ian C. Scott ${ }^{\dagger}$ \\ *Department of Biochemistry \& Molecular Biology, University of Calgary Faculty of Medicine, \\ Calgary, Alberta T2N 4 N1 Canada; '`Samuel Lunenfeld Research Institute, Mount Sinai Hospital, \\ Toronto, Ontario M5G 1 X5 Canada
}

\begin{abstract}
The placenta has been the subject of extensive basic research efforts in two distinct fields. The developmental biology of placenta has been studied because it is the first organ to develop during embryogenesis and because a number of different gene mutations in mice result in embryonic lethality due to placental defects. The trophoblast cell lineage is relatively simple such that only two major, terminally differentiated cell types appear: an "invasive trophoblast" cell subtype such as extravillous cytotrophoblast cells in humans and trophoblast giant cells in mice, and a "transport trophoblast" cell subtype that is a syncytium (syncytiotrophoblast) in humans and mice. These two cell types also have been the focus of endocrinologists because they are the source of major placental hormones. Understanding the transcriptional regulation of placental hormone genes has given insights into the control of specificity of gene expression. Because most placental hormones are produced by very specific trophoblast cell subtypes, the transcriptional details promise to give insights into cell-subtype specification. The fields of developmental biology and molecular endocrinology appear to be meeting on this common ground with the recent discovery of key transcription factors. Specifically, the basic helix-loop-helix (bHLH) transcription factor Hand1 is essential for differentiation of trophoblast giant cells in mice and also regulates the promoter for the giant cell-specific hormone, placental lactogen I gene $(P l 1)$. In contrast, formation of syncytiotrophoblast cells in mice is controlled by a distinct genetic pathway that is governed by the Gcm1 transcription factor, a homologue of the Drosophila glial cells missing gene. Human GCM1 has been shown to regulate the activity of the placental-specific enhancer of the aromatase gene (CYP19), which is specifically expressed in syncytiotrophoblast. Together, these findings imply that some key transcription factors have the dual functions of controlling both critical cell fate decisions in the trophoblast cell lineage and later the transcription of cell subtype-specific genes unrelated to development.
\end{abstract}

\section{Introduction}

Although we leave it behind at birth, the placenta is an amazing organ that is essential for intrauterine development. It allows the embryo to implant into the uterus and transports the nutrients and oxygen necessary for fetal growth. In addition, it has a major endocrine function that helps to subvert and orchestrate several maternal physiological systems that, together, further promote fetal 
growth and survival. These functions include promoting the growth of maternal blood vessels to the implantation site and their dilation, suppression of the local immune system, promoting mammary gland development and continued production of progesterone from the corpus luteum (Linzer and Fisher, 1999; Cross et $a l$, in press). Failures in any one of these functions are associated with a range of complications of human pregnancy, including missed abortion, miscarriage, intrauterine growth restriction, and pre-eclampsia (Cross, 1996; Kingdom and Kaufmann, 1997; Cross, 1999). Aside from these specific functional aspects, study of the placenta gives insights into general aspects of developmental biology that are applicable to other systems. Indeed, because of the relative simplicity of the placental cell lineages, combined with the fact that the placenta is so sensitive to genetic perturbation, the placenta is an attractive model system for understanding the control of stem cells, cell lineage, and cell-cell interactions (Cross, 2000; Hemberger and Cross, 2001).

The placenta is derived from two major cell lineages (Cross et al., 1994; Cross, 2000). Trophectoderm of the blastocyst is the precursor to the trophoblast cell lineage that will give rise to the epithelial parts of the placenta. Extraembryonic mesoderm gives rise to the stromal cells and blood vessels of the placenta. In rodents and primates, the outer layer of the mature fetal placenta consists of cells that are inherently invasive and associate with maternal blood vessels (called extravillous cytotrophoblast cells in primates and trophoblast giant cells in rodents). The innermost layer of the placenta consists of villous, tree-like branches that provide a large surface area for nutrient and gas exchange (called chorionic villi in primates and "the labyrinth" in rodents). The villi are covered with multinucleated syncytiotrophoblast (two layers in rodents) and also contain trophoblast stem cells, stromal cells, and blood vessels. The middle layer of the rodent and primate placenta consists of densely packed trophoblast cells called cytotrophoblast cell columns in primates and the spongiotrophoblast layer in rodents. Its function may simply be structural to support the underlying villi, although the spongiotrophoblast cells in rodents secrete a number of polypeptide hormones (Soares et al., 1996,1998; Linzer and Fisher, 1999). In addition, the cells may represent a reserve of precursors of the invasive trophoblast population. This idea is based on the observation, made in both human (Damsky et al., 1992,1994) and murine (Carney et al., 1993) systems, that while trophoblast stem cells spontaneously differentiate into their invasive derivatives in vitro, along the way, they progress through a stage typical of the intermediate cell layer.

The differentiation of trophoblast stem cells to either "invasive trophoblast" or syncytiotrophoblast represents the fundamental, alternative cell fate decision in the trophoblast lineage (Figure 1). Along the way to forming these two different cell types, different genetic programs are initiated and include differences in hormone gene expression. One approach to understanding differences in cell-differentiation programs at a genetic level has been to study the transcrip- 


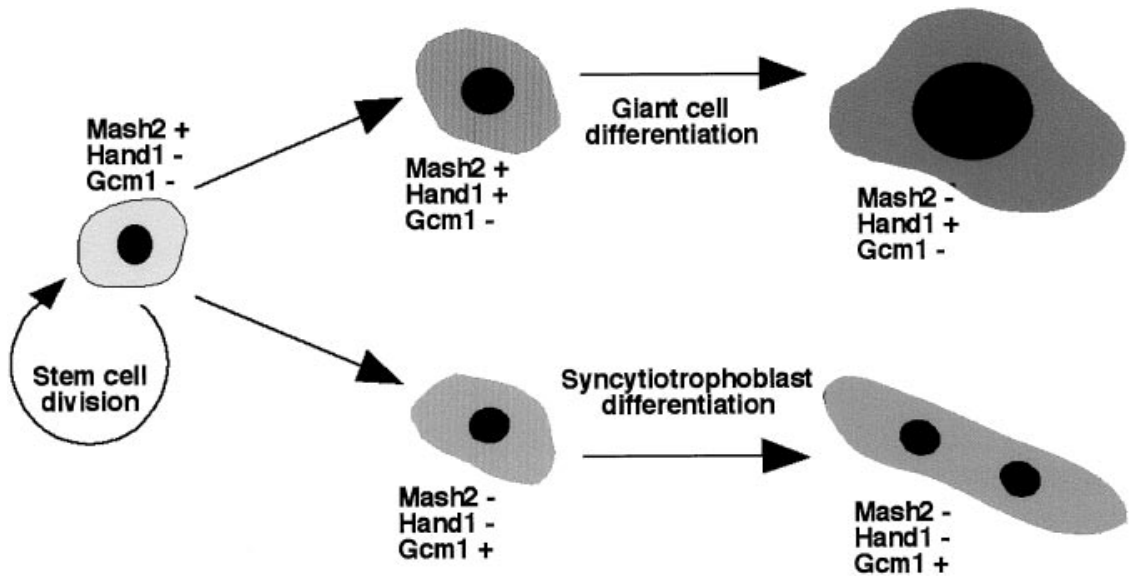

FIG. 1. Summary of the trophoblast cell lineage outlining the alternative differentiated trophoblast cell fates and the expression of key regulatory transcription factors. + indicates that the gene is expressed, whereas - indicates that the gene is not expressed.

tional mechanisms that regulate these trophoblast cell subtype-specific hormones. This approach has been very successful in other systems. An example is Pit-1, which was discovered for its ability to regulate pituitary hormone gene expression and later turned out to be essential for organ development as well (Andersen and Rosenfeld, 2001). Several different hormone genes have been intensively studied. For example, placental lactogen (Pll and $P l 2)$ and several prolactinrelated protein genes are expressed exclusively by the trophoblast giant cell subtype in rodents (Linzer and Fisher, 1999). Their promoters have been intensively characterized in both transfected cells and transgenic mice (Shida et al., 1992,1993; Vuille et al., 1993; Ma et al., 1997; Lin and Linzer, 1998; Sun and Duckworth, 1999; Ma and Linzer, 2000). The Cyp19 gene, which encodes the aromatase enzyme involved in estrogen biosynthesis, is an example of a gene that is exclusively expressed in the syncytiotrophoblast cell subtype (Hinshelwood et al., 1995; Yamada et al., 1995,1999; Kamat et al., 1998,1999). Curiously, while estrogen is produced by syncytiotrophoblast in the human placenta, the mouse placenta does not make estrogen or express Cyp19. However, when transgenic mice are made using the human gene promoter, the transgene is expressed in syncytiotrophoblast cells of the labyrinth (Kamat et al., 1999). This implies that the mouse cells must have the transcription factors that are necessary to regulate the gene appropriately. Why the endogenous mouse Cyp19 gene is not expressed likely reflects differences with the human gene in the gene sequence itself. 
The alternative approach to finding transcription factors necessary for development has been to simply clone new members of transcription factor families that have an "evolutionary history" of regulating cell fate decisions during development. Some of these gene families were first identified in lower organisms such as Drosophila melanogaster. Such families include homeobox and basic helix-loop-helix (bHLH) genes that encode "master" regulators of development. We have taken this latter approach and have, as a result, identified a transcription factor that underlies the development of trophoblast giant cells (Hand1) and another critical for syncytiotrophoblast development $(\mathrm{Gcm} 1)$ in mice.

\section{Molecular Basis of Placental Trophoblast Cell Development}

\section{A. TROPHOBLAST GIANT CELLS}

Considerable genetic evidence indicates that bHLH transcription factors function as cell-lineage determinants in a variety of cell lineages. This was first demonstrated by studies of skeletal muscle development in mammals (MyoD, Myogenin, Mrf4, Myf5), and in mesoderm (twist) and neuronal cell differentiation in Drosophila (achaete-scute) (Olson, 1990; Jan and Jan, 1993; Olson and Klein, 1994). Members of the bHLH family are thought to function as heterodimers, typically between the cell subtype-specific factors and the widely expressed $\mathrm{E}$ proteins, such as E12/E47 (which are products of the E2A gene) (Murre et al., 1991), HEB (Hu et al., 1992), and ITF2 (Henthorn et al., 1990). The ability of cell subtype-specific factors to heterodimerize with $\mathrm{E}$ factors provided a functional means of cloning new members of the family. Cloning of genes based on such functional characteristics was revolutionized 10 years ago with the development of two techniques that relied on protein-protein interaction properties of gene products. Yeast two-hybrid screening relies on interactions of proteins in transformed yeast cells. An alternative method based on phage expression of target proteins, called "interaction cloning," uses a labeled bait protein to screen the library (Blanar and Rutter, 1992). The advantage of the latter is that the approach could be used with existing $\lambda$ gt11 or $\lambda$-based cDNA libraries.

The Handl cDNA was cloned independently by three different groups and was originally given the different names Hxt, eHand, and Thingl (Cross et al., 1995; Cserjesi et al., 1995; Hollenberg et al., 1995). Using an interaction cloning approach with an E47 bait protein, Handl was isolated from a blastocyst stage cDNA library (Cross et al., 1995). Later, it was shown that Handl mRNA is expressed in trophoblast cells of the placenta and also in several structures of the embryo proper (Cross et al., 1995; Cserjesi et al., 1995; Hollenberg et al., 1995). The original blastocyst library was made using sheep blastocysts, yet a mouse homologue was found to be expressed in mouse blastocysts and later the placenta 
(Cross et al., 1995). The choice of library was partly convenience, as a similar mouse library was not available at the time. However, given the differences in placental morphology among mammalian species (Wooding and Flint, 1994), the selection of a bHLH factor that was expressed in both mouse and sheep increased the level of stringency of the screen for factors important for fundamentally conserved aspects of placental development. Most of the subsequent work has concentrated on dissecting the functions of Handl using the mouse as a model system.

The initial evidence that Handl might regulate the differentiation of trophoblast giant cells came from the expression pattern of the gene during early mouse development. At early post-implantation stages, Handl mRNA is not detectable by in situ hybridization in trophoblast stem cells of the chorion layer. It appears to be upregulated in the ectoplacental cone (the precursor to the spongiotrophoblast) and is most highly expressed in the trophoblast giant cell layer surrounding the implanted conceptus (Cross et al., 1995; Scott et al., 2000). This early pattern persists through later stages of development such that Handl mRNA is detectable in spongiotrophoblast and trophoblast giant cells. To test the function of Handl, the gene was overexpressed in Rcho- 1 cells, a rat trophoblast tumor (choriocarcinoma) cell line. It has the interesting property that the dividing cells will spontaneously differentiate into postmitotic cells that eventually take on the morphological, cell-cycle, and gene-expression profile characteristics of giant cells (Faria and Soares, 1991; Hamlin et al., 1994; Cross et al., 1995; MacAuley et al., 1998). Because the rate of giant cell transformation is normally relatively low when the cells are maintained under growth conditions, it affords the opportunity to detect the effect of factors that promote giant cell differentiation. Overexpression of Handl promotes cell proliferation arrest and giant cell differentiation in transfected Rcho-1 cells (Cross et al., 1995). A similar effect has been observed in primary trophoblast stem cell lines (I.C. Scott and J.C. Cross, unpublished data).

The real test of Handl function was the generation of Handl-deficient mice through gene targeting. Embryos that are homozygous for a Handl null mutation do not survive beyond embryonic day (E) 8.5-9.0 and, in terms of their overall size, do not progress beyond E7.5-8.0 (Firulli et al., 1998; Riley et al., 1998). The mutants are recognizable at E8.5 because of their overall reduced size, a failure of the embryo proper to undergo its characteristic turning and blebbing of the yolk sac. In the placenta, the ectoplacental cone is smaller than normal (Riley et al., 1998). The outer layer of trophoblast cells, which should contain trophoblast giant cells, has several defects in the Handl mutants (Figure 2). First, the outer layer has many fewer cells than normal and, as a result, the overall conceptus is within a much smaller sac (Riley et al., 1998; Scott et al., 2000). The number of cells present is not significantly different than the number of trophectoderm cells present at the blastocyst stage. Normally, this number increases as new giant cells differentiate at the edge of the ectoplacental cone. Differences in 


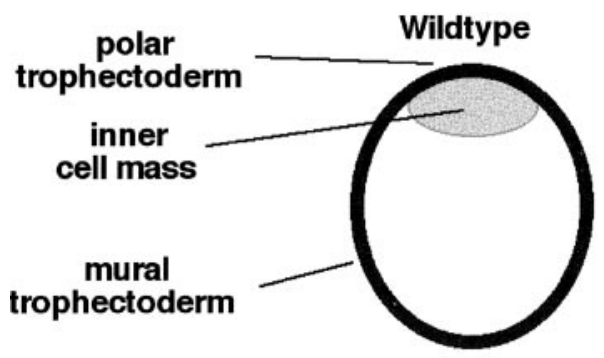

E4.5

Hand1 Mutant
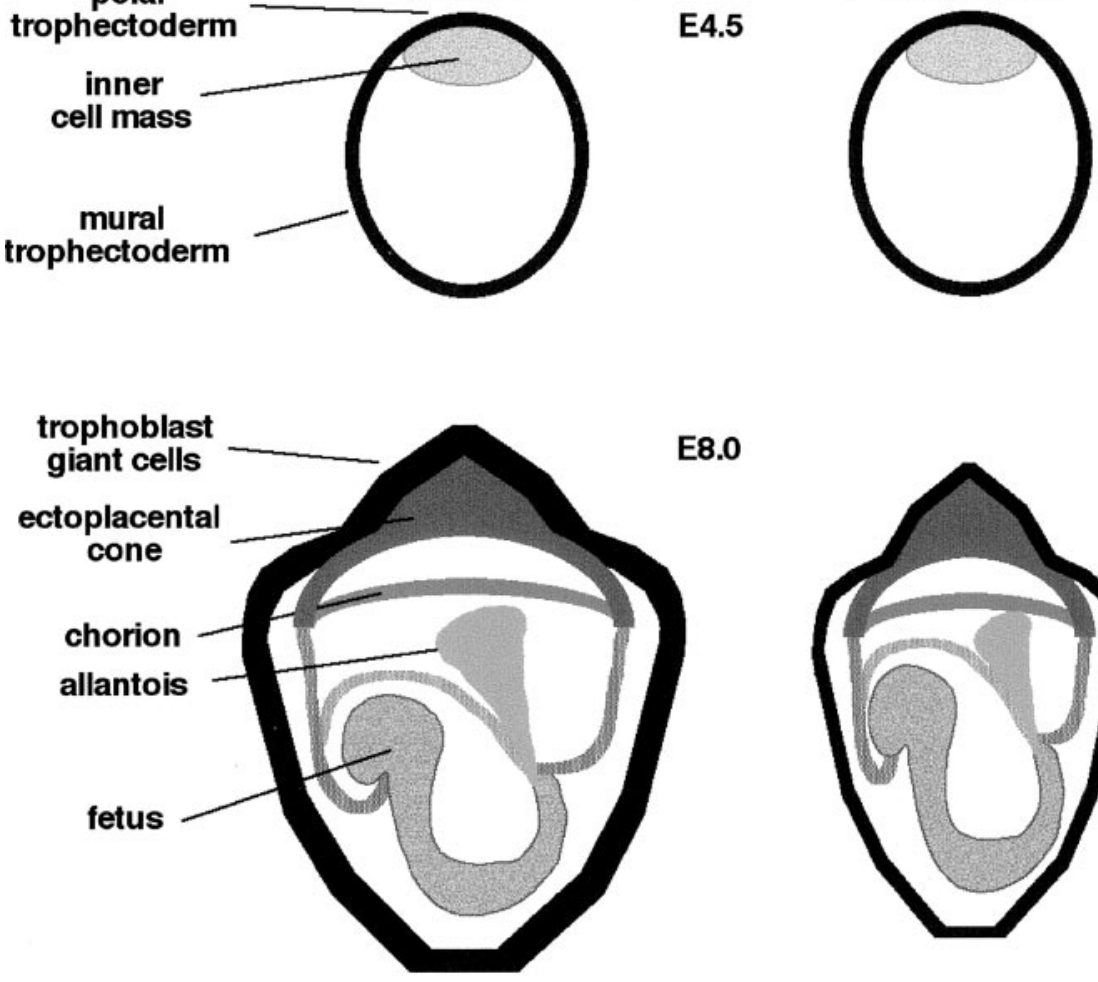

E8.0

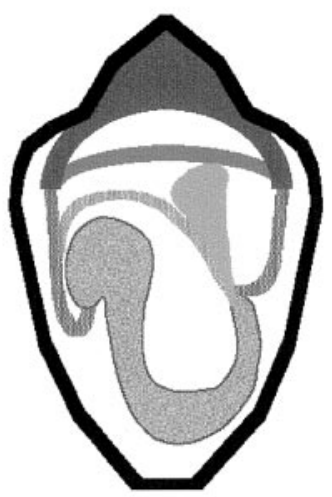

FIG. 2. Summary of the development of Handl null mutant conceptuses at embryonic day (E) 4.5 and 8.0

gene-expression patterns are consistent with the conclusion that this secondary differentiation does not occur (Riley et al., 1998). The second major difference is that the trophoblast cells in the outer layer of the placenta, which are present in the Handl mutants, failed to undergo the characteristic morphological giant transformation (Riley et al., 1998; Scott et al., 2000). Therefore, Handl is essential for trophoblast giant cell differentiation.

While Handl promotes differentiation of trophoblast giant cells, another bHLH gene has the opposite effect. Mash2 is required for the maintenance of giant cell precursors (Guillemot et al., 1994) and its overexpression in Rcho-1 cells prevents giant cell differentiation (Cross et al., 1995; Kraut et al., 1998; Scott et al., 2000). Handl and Mash2 mRNA expression overlaps in the ectoplacental cone and spongiotrophoblast, layers of the placenta that contain giant cell precursors (Scott et al., 2000). This observation implies that the 
opposing activities of Hand 1 and Mash 2 must be coordinated. Handl function is required to turn off Mash 2 mRNA expression coincident with trophoblast giant cell differentiation (Riley et al., 1998). In addition, the Hand1 protein can compete with Mash2 for binding to E proteins (Scott et al., 2000). Because Mash2 must dimerize with an E protein in order to bind DNA and therefore regulate transcription, this competition can titrate away Mash2 function. However, the Handl null mutant phenotype is not solely explained by ectopic activity of Mash2, as the Handl mutant phenotype is not altered by further mutation of Mash2 (Scott et al., 2000). Although the Hand1 protein dimerizes with E proteins in vitro, the latter do not appear to be expressed in trophoblast giant cells (Scott et al., 2000). This suggests that Hand1 likely dimerizes with some other factor(s) in these cells. Candidates include Hand1 itself, since Hand1 can homodimerize at least in vitro (Firulli et al., 2000; Scott et al., 2000). Another bHLH protein encoded by the Stral3 gene is expressed in trophoblast giant cells (Boudjelal et al., 1997) but its ability to interact with Hand1 has not been tested. The complexity of the multiple potential bHLH protein interactions involving Hand1 has been one factor that has slowed the identification of Hand1 DNA recognition site(s) and target genes. One likely scenario is that Hand1 complexed with different partner proteins has different DNA binding specificities.

\section{B. PLACENTAL VILLI AND SYNCYTIOTROPHOBLAST}

While bHLH genes regulate the formation of trophoblast giant cells, no bHLH genes have been discovered that directly regulate the differentiation of syncytiotrophoblast cells or the villous structures of the labyrinth. The Mash2 and Handl genes are expressed focally within the labyrinth layer in mice but neither pattern of expression is obviously localized to syncytiotrophoblast. While we have found other bHLH factors that are expressed in the labyrinth (I.C. Scott, K. Dawson, J.C. Cross, unpublished observations), none have shown syncytiotrophoblast-specific expression.

In looking for other transcription factors that control cell-fate decisions, we became interested in the Gcm (for glial cells missing) gene family. In Drosophila, Gcm mutants show a cell fate change in the nervous system such that precursor cells that normally divide to give rise to neural and glial derivatives instead only give rise to neurons (Wegner and Riethmacher, 2001). The gene name is slightly misleading because the mutants also show defects in hemocyte development, implying that $\mathrm{Gcm}$ regulates cell fate in general rather than specifies glial cell fate. The first reports describing attempts to identify mammalian homologues of $\mathrm{Gcm}$ revealed two genes in both mice and humans that were called $G \mathrm{cml} / \mathrm{Gcm}-a$ and $G \mathrm{~cm} 2 / G \mathrm{~cm}-b$ (Akiyama et al., 1996; Altshuller et al., 1996; Kim et al., 1998). The initial published report indicating that $\mathrm{Gcml} \mathrm{mRNA}$ was only detected in the placenta, based on northern blotting (Altshuller et al., 1996), prompted further investigation. It soon was discov- 
ered that expression of $\mathrm{Gcml}$ in the mouse placenta is confined to the labyrinth layer (Kim et al., 1998; Basyuk et al., 1999), including syncytiotrophoblast cells (Basyuk et al., 1999). Expression initiates at the time that the labyrinth first begins to form at E8.5 and persists as long as the labyrinth grows through repeated branching morphogenesis (Basyuk et al., 1999).

Detailed mRNA expression analysis has shown that $\mathrm{Gcml}$ gene expression is initiated around E8.0-8.5 in small clusters of cells within the chorion layer that otherwise contains trophoblast stem cells (Anson-Cartwright et al., 2000). These $\mathrm{Gcml}$ expressing cells are found at sites where the chorionic plate folds to form branches, regions where syncytiotrophoblast differentiation also begins. Both the initiation of chorioallantoic branching (Figure 3) and the formation of syncytiotrophoblast are blocked completely when Gcml function is ablated (Anson-Cartwright et al., 2000). As a result, the labyrinth layer of the placenta does not form in Gcml null mutants and the chorion layer persists (AnsonCartwright et al., 2000; Schreiber et al., 2000). Without the labyrinth, the embryos die around E10. Given that Gcm in the Drosophila nervous system

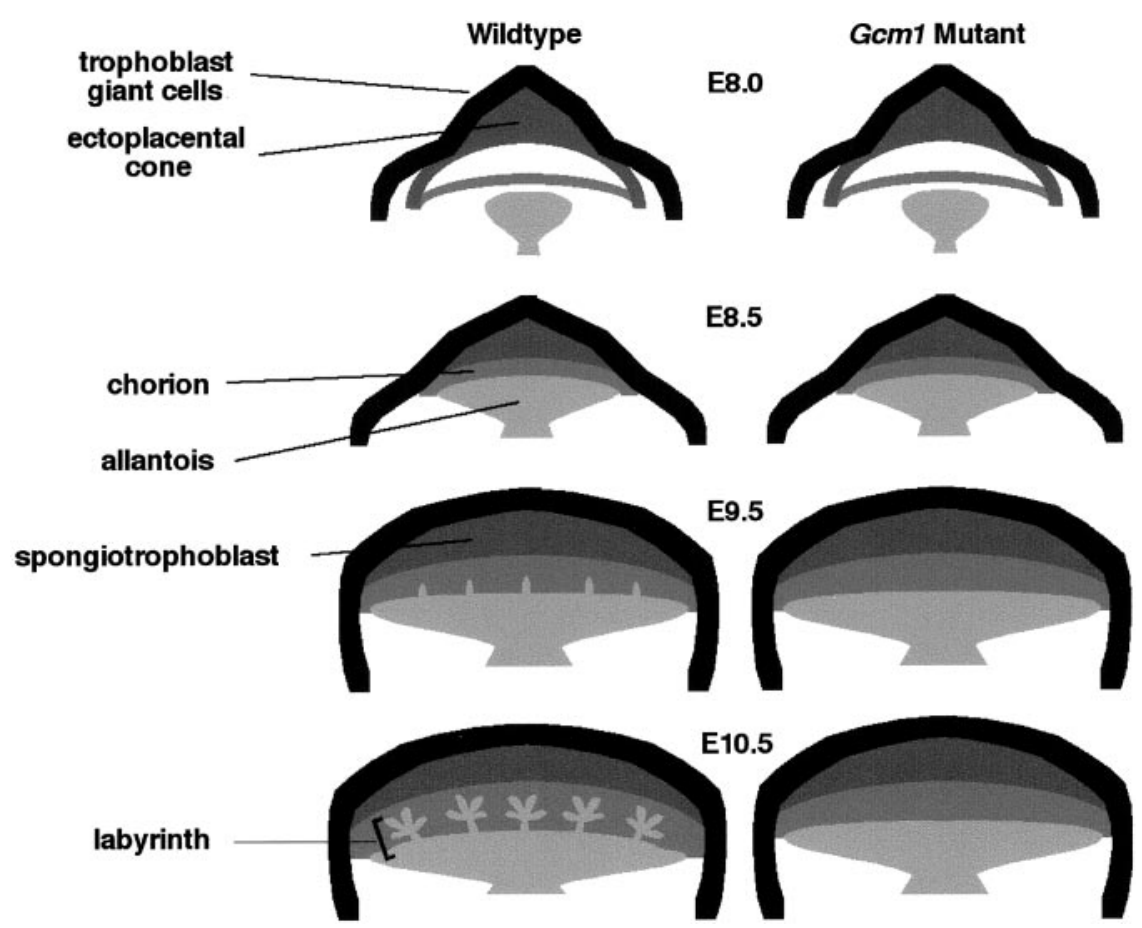

FIG. 3. Summary of the development of $G \mathrm{~cm} 1$ null mutant conceptuses between embryonic day (E) 8.0 and 10.5 . 
regulates a cell-fate change, it is interesting to consider what happens in the Gcml-deficient mice and whether the phenotype can be interpreted in a similar way. Because the chorionic trophoblast cell lineage has not been described in detail, this is a matter for speculation only. However, a reasonable hypothesis is that $G \mathrm{cml}$ is required for trophoblast cells to "choose" a syncytiotrophoblast fate rather than remain as stem cells.

\section{Transcription Factors Controlling Development Also Regulate Placental Hormone Production}

Both Hand1 and Gcm1 were discovered as orphan transcription factors in the sense that, although their DNA-binding specificities were learned early on, their biologically important target genes remain largely unknown. It is safe to say that this is true for the vast majority of transcription factors that have been described. The criteria that prove that a transcription factor is an important and direct regulator of a gene are 1) the transcription regulatory regions of the gene should contain binding sites for the factor, 2) selective mutation of the binding site should alter gene expression, and 3) gene expression should be similarly reduced in mutants lacking the transcription factor. Trophoblast subtype-specific hormone genes fulfill some of these criteria and suggest them as target genes of Hand1 and Gcm1.

The mouse $P l l$ gene (encoding the prolactin-like hormone, placental lactogen I) is specifically expressed in trophoblast giant cells (Faria et al., 1991). The expression of $P l l$ mRNA is dramatically reduced in Handl mutants, indicating that $P l l$ is genetically downstream of Handl (Firulli et al., 1998; Riley et al., 1998). Because Handl mutants show other abnormalities in giant cell differentiation, the reduced expression in the mutants could be indirect. However, the mouse Pll promoter contains a variant E-box-like element (Figure 4) that conforms to the consensus site to which Hand1/E47 dimers can bind (Hollenberg et al., 1995). Although a point mutation of this site has not been tested, deletion of a 86-bp region of the promoter (between -274 and -188 relative to the transcription start site) that encompasses this element results in a reduction in overall promoter activity in transfected Rcho-1 trophoblast giant cells (Figure 4) (Shida et al., 1993). Co-transfection of Handl expression vector with a Pll promoter/reporter gene construct results in dose-dependent transactivation (Figure 4) (Cross et al., 1995; Scott et al., 2000). Deletion of the promoter between -274 and -188 prevents transactivation by Hand1 (Cross et al., 1995). These data suggest that Hand 1 likely regulates $P l l$ gene promoter activity directly. It is important to note, however, that Hand1 must not provide cell-type specificity to $P l l$ transcription on its own because the Handl gene is expressed in other cells and tissues where Pll is not. For example, in the trophoblast lineage, Handl is expressed in the ectoplacental cone/spongiotrophoblast (Cross et al., 1995; Scott et al., 2000). It is likely that Hand 1 interactions with other trophoblast subtype- 


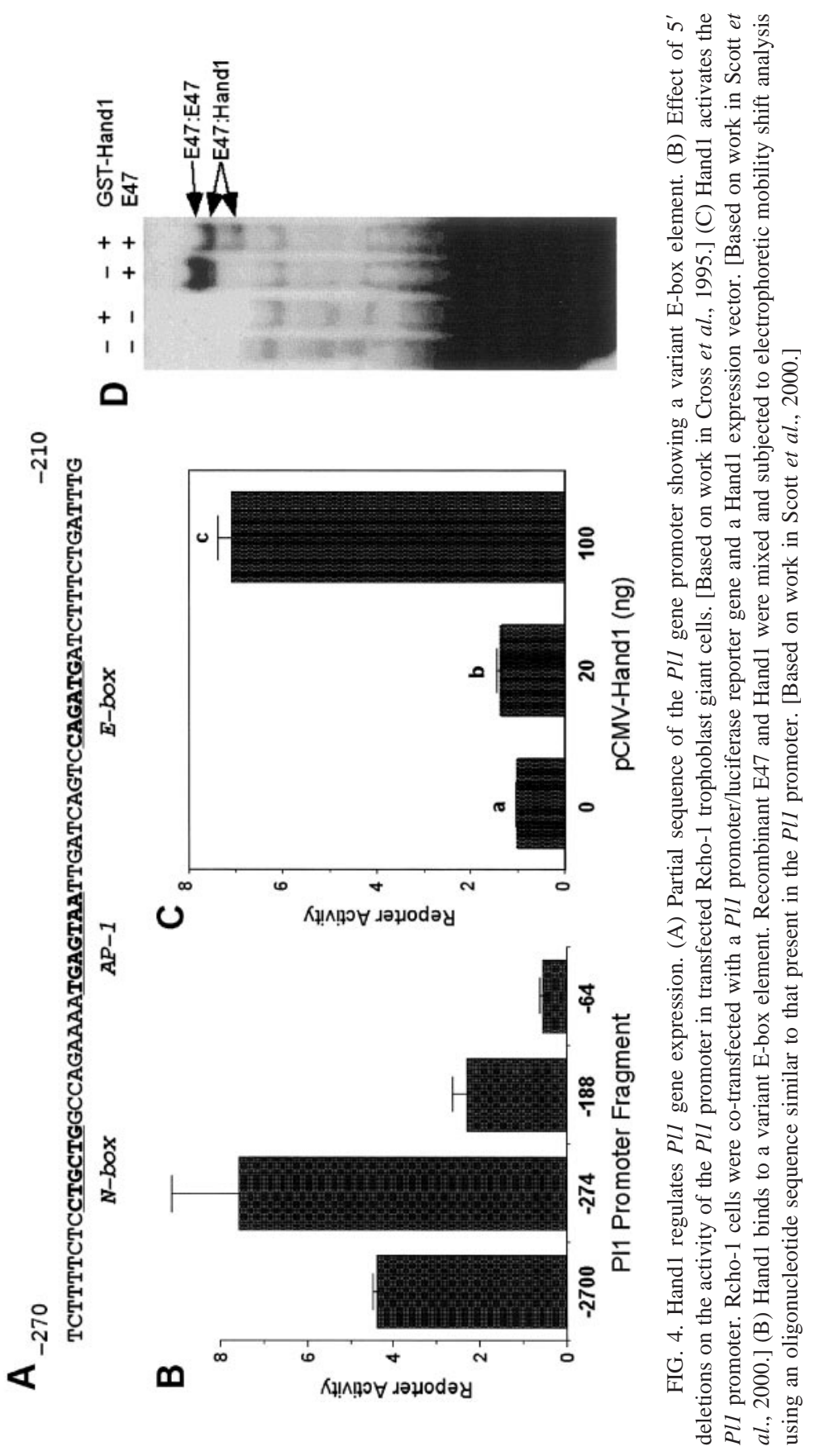


specific transcription factors together provide the specificity to $P l l$ gene expression. These other factors could include Gata factors (Ng et al., 1994) and/or the bHLH factor Stra13 (Boudjelal et al., 1997).

In contrast to the directed studies aimed at making a connection between Hand1 and Pll transcription, the $\mathrm{Gcm} 1$ transcription factor has been associated with regulation of the Cyp19 gene but by a more indirect route. In characterizing the Cyp19 promoter by conventional molecular and biochemical means, Yamada and colleagues localized a critical regulatory element to a short region of DNA designated TSE2 (Yamada et al., 1999). The TSE2 element was used in a one-hybrid screen in which DNA sequences are employed as the bait to identify transcription factors able to bind it. This screen identified a single cDNA clone from a human placental cDNA library that turned out to encode GCM1. In retrospect, the critical regulatory element fit the known consensus for a Gcm1/GCM1-binding element (Schreiber et al., 1997,1998). Yamada also showed that a similar DNA sequence was present in the placental enhancer of the leptin gene (Yamada et al., 1999). What is obviously missing from the analysis is proof that Gcm1/GCM1 is critical for transcriptional regulation of Cyp19 and Leptin but the data thus far appear quite compelling.

\section{Conclusions}

How do we interpret the observations that, while the Hand1 and $\mathrm{Gcm} 1$ transcription factors are critical for development of distinct trophoblast cell subtypes, they also appear to regulate cell subtype-specific genes? In the case of the hormone genes implicated to date, it seems unlikely that their function underlies the developmental roles of their transcriptional regulators. A more likely explanation is simply that what has been observed in other systems holds true in trophoblast cells as well: transcription factors controlling cellular development have ongoing effects in the same cells to regulate the transcription of genes whose function is peculiar to those cells. Not so many years ago, it was argued that studying the promoters of cell type-specific genes, as a means of getting insights into transcription factors that control cell fate, would be an endless road. As regulators would be identified, the search would turn to "the regulators of the regulators," and so on. If the Pll and Cyp19 genes are any indication, however, the procession from key transcription factor to cell type-specific gene may be much less complex and, indeed, can occur in a single step without need for a cascade of gene-induction events. With the discovery that the human genome may contain many fewer genes than originally thought, in retrospect, it may make sense that regulatory networks would involve fewer steps.

\section{ACKNOWLEDGMENTS}

Supported by operating grants from the Canadian Institutes of Health Research (CIHR). J.C.C. is a CIHR Investigator and a Senior Scholar of the Alberta Heritage Foundation for Medical Research. 


\section{REFERENCES}

Akiyama Y, Hosoya T, Poole AM, Hotta Y 1996 The Gcm-motif: a novel DNA-binding motif conserved in Drosophila and mammals. Proc Natl Acad Sci USA 93:14912-14916

Altshuller Y, Copeland NG, Gilbert DJ, Jenkins NA, Frohman MA $1996 \mathrm{Gcml}$, a mammalian homolog of Drosophila Glial Cells Missing. FEBS Lett 393:201-204

Andersen B, Rosenfeld MG 2001 POU domain factors in the neuroendocrine system: lessons from developmental biology provide insights into human disease. Endocr Rev 22:2-35.

Anson-Cartwright L, Dawson K, Holmyard D, Fisher SJ, Lazzarini RA, Cross JC 2000 The glial cells missing-1 protein is essential for branching morphogenesis in the chorioallantoic placenta. Nature Genet 25:311-314

Basyuk E, Cross JC, Corbin J, Nakayama H, Hunter PJ, Nait-Oumesmar B, Lazzarini RA 1999 The murine $\mathrm{Gcm} 1$ gene is expressed in a subset of placental trophoblast cells. Dev Dynam 214:303-311

Blanar MA, Rutter WJ 1992 Interaction cloning: identification of a helix-loop-helix zipper protein that interacts with c-Fos. Science 256:1014-1018

Boudjelal M, Taneja R, Matsubara S, Bouillet P, Dolle P, Chambon P 1997 Overexpression of Stra13, a novel retinoic acid-inducible gene of the basic helix-loop-helix family, inhibits mesodermal and promotes neuronal differentiation of P19 cells. Genes Dev 11:2052-2065

Carney EW, Prideaux V, Lye SJ, Rossant J 1993 Progressive expression of trophoblast-specific genes during formation of mouse trophoblast giant cells in vitro. Mol Reprod Dev 34:357-368

Cross JC 1996 Trophoblast function in normal and preeclamptic pregnancy. Fetal Matern Med Rev 8:57-66

Cross JC 1999 Molecular regulation of placental development. In: Baker PN, Kingdom JCP, eds. Intrauterine Growth Restriction. London: Springer-Verlag; 387-400

Cross JC 2000 Genetic insights into trophoblast differentiation and placental morphogenesis. Semin Cell Dev Biol 11:105-113

Cross JC, Werb Z, Fisher SJ 1994 Implantation and the placenta: key pieces of the development puzzle. Science 266:1508-1518

Cross JC, Flannery ML, Blanar MA, Steingrimsson E, Jenkins NA, Copeland NG, Rutter WJ, Werb Z 1995 Hxt encodes a basic helix-loop-helix transcription factor that regulates trophoblast cell development. Development 121:2513-2523

Cross JC, Hemberger M, Lu Y, Nozaki T, Whiteley K, Masutani M, Adamson SL 2002 Trophoblast functions, angiogenesis and remodeling of the maternal vasculature in the placenta. Mol Cell Endocrinol, in press

Cserjesi P, Brown D, Lyons GE, Olson EN 1995 Expression of the novel basic helix-loop-helix gene $e H A N D$ in neural crest derivatives and extraembryonic membranes during mouse development. Dev Biol 170:664-678

Damsky CH, Fitzgerald ML, Fisher SJ 1992 Distribution patterns of extracellular matrix components and adhesion receptors are intricately modulated during first trimester cytotrophoblast differentiation along the invasive pathway in vivo. J Clin Invest 89:210-222

Damsky CH, Librach C, Lim KH, Fitzgerald ML, McMaster MT, Janatpour M, Zhou Y, Logan SK, Fisher SJ 1994 Integrin switching regulates normal trophoblast invasion. Development 120:3657-3666

Faria TN, Soares MJ 1991 Trophoblast cell differentiation: establishment, characterization, and modulation of a rat trophoblast cell line expressing members of the placental prolactin family. Endocrinology 129:2895-2906

Faria TN, Ogren L, Talamantes F, Linzer DIH, Soares MJ 1991 Localization of placental lactogen-I in trophoblast giant cells of the mouse placenta. Biol Reprod 44:327-331 
Firulli AB, McFadden DG, Lin Q, Srivastava D, Olson EN 1998 Heart and extra-embryonic mesodermal defects in mouse embryos lacking the bHLH transcription factor Hand1. Nature Genet 18:266-270

Firulli BA, Hadzic DB, McDaid JR, Firulli AB 2000 The basic helix-loop-helix transcription factors dHAND and eHAND exhibit dimerization characteristics that suggest complex regulation of function. J Biol Chem 275:33567-33573

Guillemot F, Nagy A, Auerbach A, Rossant J, Joyner AL 1994 Essential role of Mash-2 in extraembryonic development. Nature 371:333-336

Hamlin GP, Lu XJ, Roby KF, Soares MJ 1994 Recapitulation of the pathway for trophoblast giant cell differentiation in vitro: stage-specific expression of members of the prolactin gene family. Endocrinology 134:2390-2396

Hemberger M, Cross JC 2001 Genes governing placental development. Trends Endocrinol Metab 12:162-168

Henthorn P, Kiledjian M, Kadesch T 1990 Two distinct transcription factors that bind the immunoglobulin enhancer uE5/kE2 motif. Science 247:467-470

Hinshelwood MM, Liu Z, Conley AJ, Simpson ER 1995 Demonstration of tissue-specific promoters in nonprimate species that express aromatase P450 in placentae. Biol Reprod 53:1151-1159

Hollenberg SM, Sternglanz R, Cheng PF, Weintraub H 1995 Identification of a new family of tissue-specific basic helix-loop- helix proteins with a two-hybrid system. Mol Cell Biol 15:3813-3822

Hu JS, Olson EN, Kingston RE 1992 HEB, a helix-loop-helix protein related to E2A and ITF2 that can modulate the DNA-binding ability of myogenic regulatory factors. Mol Cell Biol 12:1031-1042

Jan YN, Jan LY 1993 Functional gene cassettes in development. Proc Natl Acad Sci USA 90:8305-8307

Kamat A, Alcorn JL, Kunczt C, Mendelson CR 1998 Characterization of the regulatory regions of the human aromatase (P450arom) gene involved in placenta-specific expression. Mol Endocrinol 12:1764-1777

Kamat A, Graves KH, Smith ME, Richardson JA, Mendelson CR 1999 A 500-bp region, approximately $40 \mathrm{~kb}$ upstream of the human CYP19 (aromatase) gene, mediates placentaspecific expression in transgenic mice. Proc Natl Acad Sci USA 96:4575-4580

Kim J, Jones BW, Zock C, Chen Z, Wang H, Goodman CS, Anderson DJ 1998 Isolation and characterization of mammalian homologs of the Drosophila gene glial cells missing. Proc Natl Acad Sci USA 95:12364-12369

Kingdom JCP, Kaufmann P 1997 Oxygen and placental villous development: origins of fetal hypoxia. Placenta 18:613-621

Kraut N, Snider L, Chen C, Tapscott SJ, Groudine M 1998 Requirement of the mouse I-mfa gene for placental development and skeletal patterning. EMBO J 17:6276-6288

Lin J, Linzer DI 1998 Identification of trophoblast-specific regulatory elements in the mouse placental lactogen II gene. Mol Endocrinol 12:418-427

Linzer DI, Fisher SJ 1999 The placenta and the prolactin family of hormones: regulation of the physiology of pregnancy. Mol Endocrinol 13:837-840

Ma GT, Roth ME, Groskopf JC, Tsai FY, Orkin SH, Grosveld F, Engel JD, Linzer DI 1997 GATA-2 and GATA-3 regulate trophoblast-specific gene expression in vivo. Development 124:907-914

Ma GT, Linzer DI 2000 GATA-2 restricts prolactin-like protein A expression to secondary trophoblast giant cells in the mouse. Biol Reprod 63:570-574

MacAuley A, Cross JC, Werb Z 1998 Reprogramming the cell cycle for endoreduplication in rodent trophoblast cells. Mol Biol Cell 9:795-807 
Murre C, Voronova A, Baltimore D 1991 B-cell- and myocyte-specific E2-box-binding factors contain E12/E47-like subunits. Mol Cell Biol 11:1156-1160

Ng YK, George KM, Engel JD, Linzer DI 1994 GATA factor activity is required for the trophoblast-specific transcriptional regulation of the mouse placental lactogen I gene. Development 120:3257-3266

Olson EN 1990 MyoD family: a paradigm for development. Genes Dev 4:1454-1461

Olson EN, Klein WH 1994 bHLH factors in muscle development: dead lines and commitments, what to leave in and what to leave out. Genes Dev 8:1-8

Riley P, Anson-Cartwright L, Cross JC 1998 The Hand1 bHLH transcription factor is essential for placentation and cardiac morphogenesis. Nature Genet 18:271-275

Schreiber J, Sock E, Wegner M 1997 The regulator of early gliogenesis glial cells missing is a transcription factor with a novel type of DNA-binding domain. Proc Natl Acad Sci USA 94:4739-4744

Schreiber J, Enderich J, Wegner M 1998 Structural requirements for DNA binding of GCM proteins. Nucleic Acids Res 26:2337-2343

Schreiber J, Riethmacher-Sonnenberg E, Riethmacher D, Tuerk EE, Enderich J, Bosl MR, Wegner M 2000 Placental failure in mice lacking the mammalian homolog of glial cells missing, GCMa. Mol Cell Biol 20:2466-2474

Scott IC, Anson-Cartwright L, Riley P, Reda D, Cross JC 2000 The Hand1 basic helix-loop-helix transcription factor regulates trophoblast giant cell differentiation via multiple mechanisms. Mol Cell Biol 20:530-541

Shida MM, Jackson-Grusby LL, Ross SR, Linzer DI 1992 Placental-specific expression from the mouse placental lactogen II gene promoter. Proc Natl Acad Sci USA 89:3864-3868

Shida MM, Ng YK, Soares MJ, Linzer DI 1993 Trophoblast-specific transcription from the mouse placental lactogen-I gene promoter. Mol Endocrinol 7:181-188

Soares MJ, Chapman BM, Rasmussen CA, Dai G, Kamei T, Orwig KE 1996 Differentiation of trophoblast endocrine cells. Placenta 17:277-289

Soares MJ, Muller H, Orwig KE, Peters TJ, Dai G 1998 The uteroplacental prolactin family and pregnancy. Biol Reprod 58:273-284

Sun Y, Duckworth ML 1999 Identification of a placental-specific enhancer in the rat placental lactogen II gene that contains binding sites for members of the Ets and AP-1 (activator protein 1) families of transcription factors. Mol Endocrinol 13:385-399

Vuille J-C, Cattini PA, Bock ME, Verstuyf A, Schroedter IC, Duckworth ML, Friesen HG 1993 Rat prolactin-like protein A partial gene and promoter structure: promoter activity in placental and pituitary cells. Mol Cell Endocrinol 96:91-98

Wegner M, Riethmacher D 2001 Chronicles of a switch hunt: gcm genes in development. Trends Genet 17:286-290

Wooding FBP, Flint APF 1994 Placentation. In: Lamming GE, ed. Marshall's Physiology of Reproduction, 4th edit. New York: Chapman and Hall; 233-460

Yamada K, Harada N, Honda S, Takagi Y 1995 Regulation of placenta-specific expression of the aromatase cytochrome P-450 gene. Involvement of the trophoblast-specific element binding protein. J Biol Chem 270:25064-25069

Yamada K, Ogawa H, Honda S, Harada N, Okazaki T 1999 A GCM motif protein is involved in placenta-specific expression of human aromatase gene. J Biol Chem 274:32279-32286 